\title{
State intervention in the domestic market restructuring: an example of the Russian sunflower market
}

\author{
Sergey U. Chernikov, and Alexander Zobov* \\ Peoples' Friendship University of Russia (RUDN University), Miklukho-Maklaya Street, 6, 117198 \\ Moscow, Russian Federation
}

\begin{abstract}
In recent years, the Russian market of sunflower oil has shown steady growth, while the key trend is the increase and deepening of exports. In 2020, the market showed an increase in exports to China and India, reaching a value of $35 \%$ of the total export volume. At the moment, Russia is considering a formula for an export duty on sunflower oil, as it struggles with food price inflation. It is assumed that the export duty on sunflower oil will be structured similarly to that used in the wheat market. The government brokered the deal to mitigate the impact of high international prices on a key domestic product, and was forced to lock in retail sunflower oil prices after domestic sunflower and sunflower oil prices began to rise following last summer's low sunflower harvest in the Black Sea region. It is expected that the introduction of a new export duty will be able to stabilize domestic food inflation.
\end{abstract}

\section{Introduction}

The global economic situation is gradually deteriorating, and global financial institutions say that the recovery will be long and uneven. Governments in the world's leading economies are pouring unprecedented amounts of liquidity into national banking and fiscal systems, but the economic impact of these measures is still negligible at best. It is obvious that the global depression will last for several years and will cause many significant changes in the economic, social, and possibly political landscape of the world.

In the current conditions of the turbulence of the world economy and the reformatting of traditional trade relations, the trends towards import substitution and self-sufficiency in large countries are becoming more pronounced. With increasing inflationary trends in world markets, States seek to protect domestic markets and jobs by closing the production circuits of their most important products within controlled economic territories - preferably their own. These transformational aspects of modern globalization have primarily affected one of the most sensitive areas of the international economy - food production. The world population continues to grow by about 80 million people a year, which directly affects the level of food security of countries. To meet the growing demand for food, many countries have focused their efforts on developing new technologies for high-tech agricultural chains,

* Corresponding author: chernikov-syu@rudn.ru 
which can significantly increase labor productivity. Typically, this is the adaptation of the latest and advanced technologies of industry 4.0 - fast-growing growth methods, growing crops in precise conditions of temperature and humidity, promoting soil fertility and balanced nutrition of crops, managing logistics chains and transport losses of crops, value added and post-harvest management, etc.

It is assumed that the application of these approaches leads to a significant transformation of the traditional format of the work of agriculture and the food industry. New agro-industrial enterprises are much less dependent on the use of water, fertilizers and pesticides in whole fields. Instead, farmers will use minimal quantities or even eliminate them completely from the supply chain. Agricultural technology startups in the world as a whole are showing steady growth, and entrepreneurs and investors are showing growing interest in this sector. Also, in the current conditions, the role of national producers of agricultural products is increasing, as opposed to large multinational corporations.

However, large monetary and non-monetary investments are necessary to implement all these technologies, and governments today seem to prioritize the exceptionally problematic issue of securing the agricultural stability at the home market. Russia has seriously turned to the ideas of self-sufficiency and import substitution in 2014, after the Ukraine crisis. The efforts led to particularly good results in agriculture and military-focused industries. In many agricultural markets Russia switched from importing to exporting activitis. However, it seems that the current global inflation issue in world economy creates a requirement in further prioritising the internal comsumption, rather that mere partial import subsititution.

This hypothesis made up the primary goal of the current article, which can be formulated as evaluating the possible consequences of further state intervention to restructuring the sunflower oil domestic market and industry. This particular market segment is an exceptionally good example due to its obvious export orientation and strong positions in the global agriculture industry.

\section{Materials and Methods}

The paper was composed on the content-analysis basis of a range of statistical resources and publications relevant to the research topic. The statistical data derived from both specialized national and international commodity databases and information portals, while the discussion points concentrate on topical journals.

\section{Results and Discussion}

\subsection{Global sunflower market outlook}

In the world market of sunflower oil, Ukraine and Russia are the permanent leaders, they hold the leading positions in international supplies of sunflower oil. In 2019, the share of exports from Russia and Ukraine covered almost $80 \%$ of the market, despite the unfavorable price situation and low trade activity. Figure 1 shows data on the world's main sunflower oil exporting countries in 2019 and changes compared to 2018. 


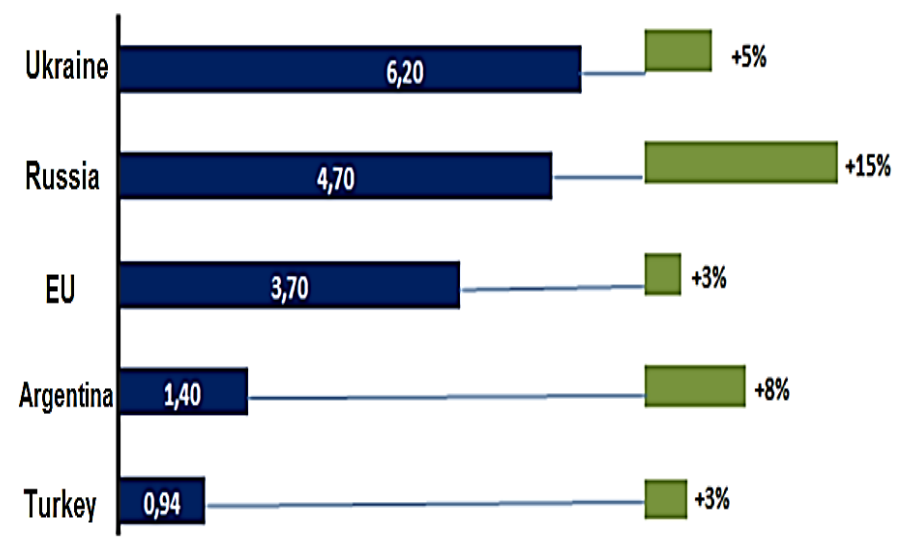

Fig. 1. Majour exporters of sunflower oil in 2019 ([1]).

The top-5 sunflower producing countries according to the FAO report include Ukraine, Russia, Argentina, Romania and China (see Figure 2).

The Asia-Pacific region is the fastest growing sunflower market. This region dominates the sunflower market in terms of consumption after Europe, occupying about $30 \%$ of the global market in 2019. India and China occupy the leading positions in exports at the country level, this is primarily due to the high marginality of exports. The market in this region is determined by consumer growth, and over the past 15 years, consumption has approximately increased fivefold.

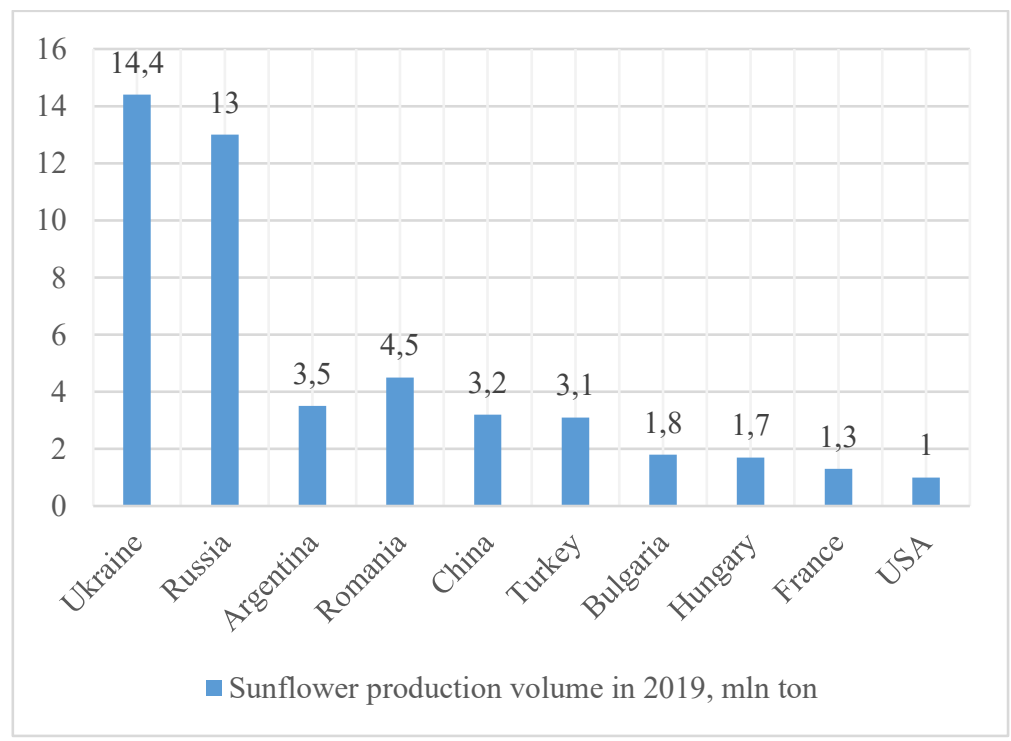

Fig. 2. Top-10 countries in terms of sunflower production in the world in 2019 [2].

Constantly growing stocks of sunflower oil in the context of increasing global consumption contributed to the expansion of supplies to the foreign market [3]. Figure 3 shows the world leaders in sunflower acreage in 2019. At the same time, the total area of sunflower crops in 2019 amounted to 26 million hectares and $69 \%$ of all crops fall on the five world leaders. 
It should be noted that, despite quite significant differences in the export capacities of the main producers, the pace of global competition remains quite high and continues to grow every year.

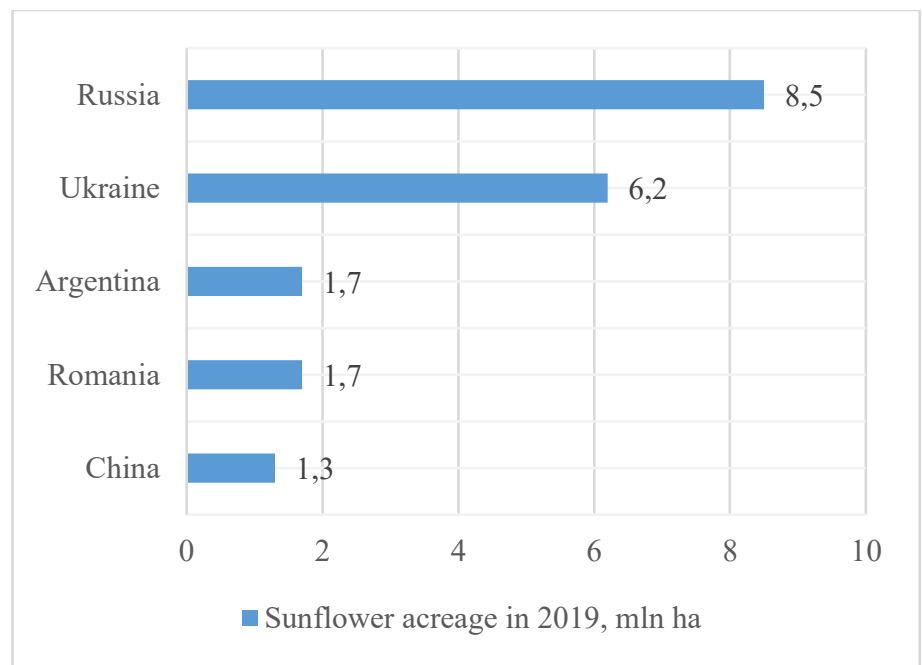

Fig. 3. Top 5 countries by sunflower acreage in 2019 [2].

Russian sunflower oil suppliers compete with Ukraine for demand from major sunflower importers in China [4]. Figure 13 shows the largest importing countries of Russian sunflower oil. Thus, the main consumers of Russian sunflower oil, according to the presented schedule, are Iran, Turkey, China and Egypt [5].

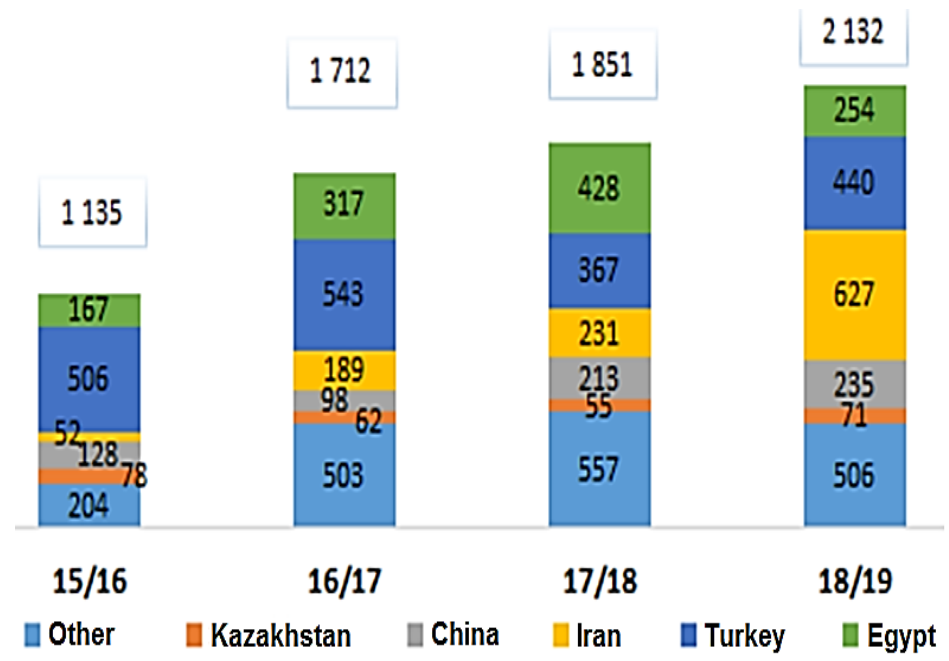

Fig. 4. Importing countries of Russian sunflower oil, thousand tons [6].

It is important to note the interrupted long-term trend of increasing sunflower production in the world [7]. The maximum volumes of oilseed harvesting stimulated the companies to increase their capacity and load the existing lines. However, according to the results of the 2020/2021 season, there was a sharp decline in production, caused by an unexpected crop failure in the leading countries of sunflower production. 


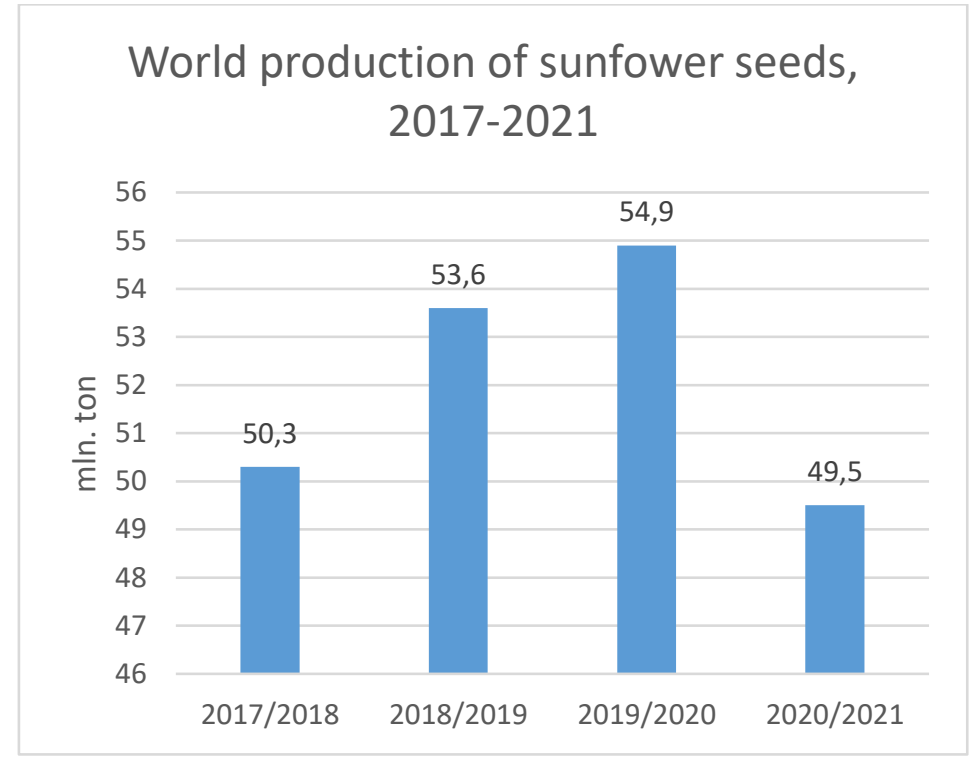

Source: composed by author from Worldwide oilseed production by type [8].

Fig. 5. Forecast of sunflower production in the world in 2017-2021.

Considering the situation on the global sunflower market, it is important to note the following trends that will continue over the next five years $[9,10]$ :

- stable growth in sunflower production and consumption, by an average of $4 \%$ per year;

- increase in the share of industrial sunflower consumption;

- market instability due to price dynamics;

- reduced yield;

- сокращение reduced acreage and reduced harvest in 2020 due to the pandemic;

- sunflower seed export growth;

- $\quad$ рост increased production of sunflower cake and meal;

- difficulties with logistics;

- rising prices for sunflower seeds and their processed products, caused by consistently high global demand, rising global prices for vegetable oils, and a reduction in the volume of sunflower seed collections.

The increase in world prices that began in the summer of 2020 was caused by unexpectedly very low production levels in Ukraine, Russia and Argentina, following the loss of a crop estimated at about 6 million tons (see Figure 6). 


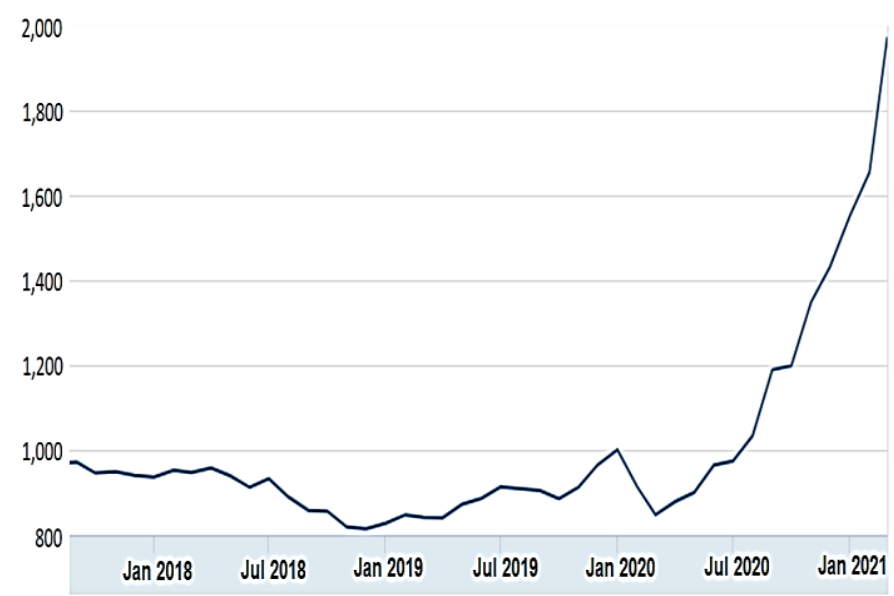

Source: fred.stlouisfed.org [11].

Fig. 6. Average price of sunflower oil on the world market per ton, USD, 2018-2021.

\subsection{Controversy of Russian sunflower market}

In Russia, the increase in sunflower prices, in addition to these factors, is also caused by the devaluation of the national currency [12]. As mentioned above, Russia is the world's second largest producer and exporter of sunflower oil after Ukraine. With the increase in refining capacity in Russia, the country is also increasing its share in the global market. Russian sunflower oil production is growing steadily, while domestic consumption will remain virtually unchanged (see Figure 7).

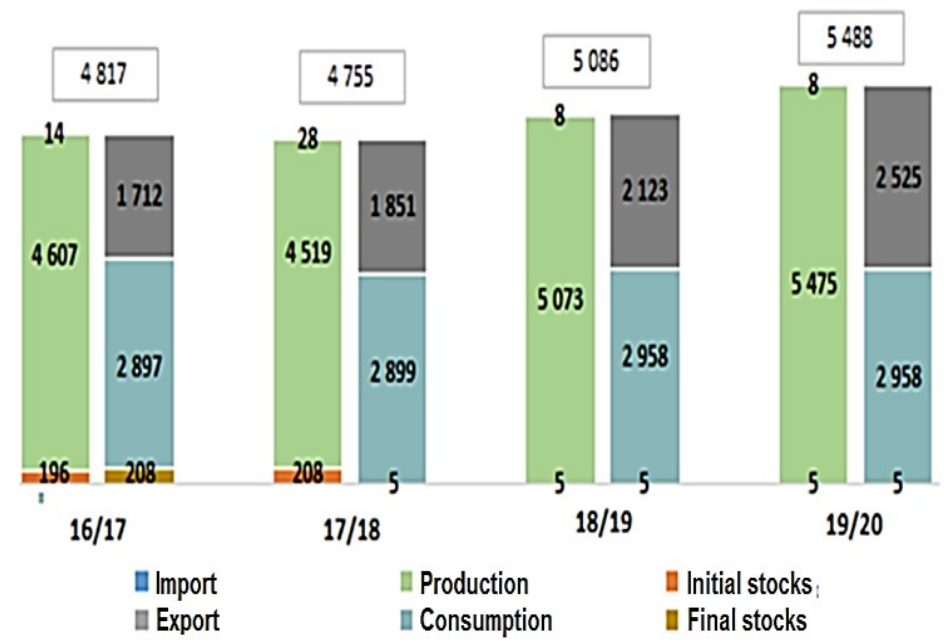

Fig. 7. Supply and demand balance of sunflower oil in Russia, thousand tons [6].

According to the FAO "Food Outlook" report, it was expected that by the end of the 2020 season, the supply of sunflower oil from Russia would reach a new level due to competitive prices and high production volume. Against this background, an increase in the supply of sunflower meal and cake from Russia was also expected. However, the forecast for the 2020/2021 season showed a drop in sunflower seed production in the Russian 
Federation against the background of a return to the average yield level. As of 2021, Russia is the world's second-largest exporter of sunflower oil after Ukraine. From Russia, deliveries are made to more than 40 countries around the world, and this number is growing from year to year. The increase in the forecast of world production and the decline in consumer demand were the main reasons for the development of large-scale rolling stocks of sunflower oil, which, in turn, affected prices and slowed down the pace of trading in the foreign market [14]. The consumption of sunflower oil in Russia is quite stable, for 2020 it is about $80 \%$ of the total consumption of vegetable oil, while $58 \%$ is accounted for by unrefined sunflower oil . Mainly, sunflower oil is used in cooking. Over the past five years, the volume of sunflower acreage in Russia has grown by more than 1 million hectares (see Figure 8).

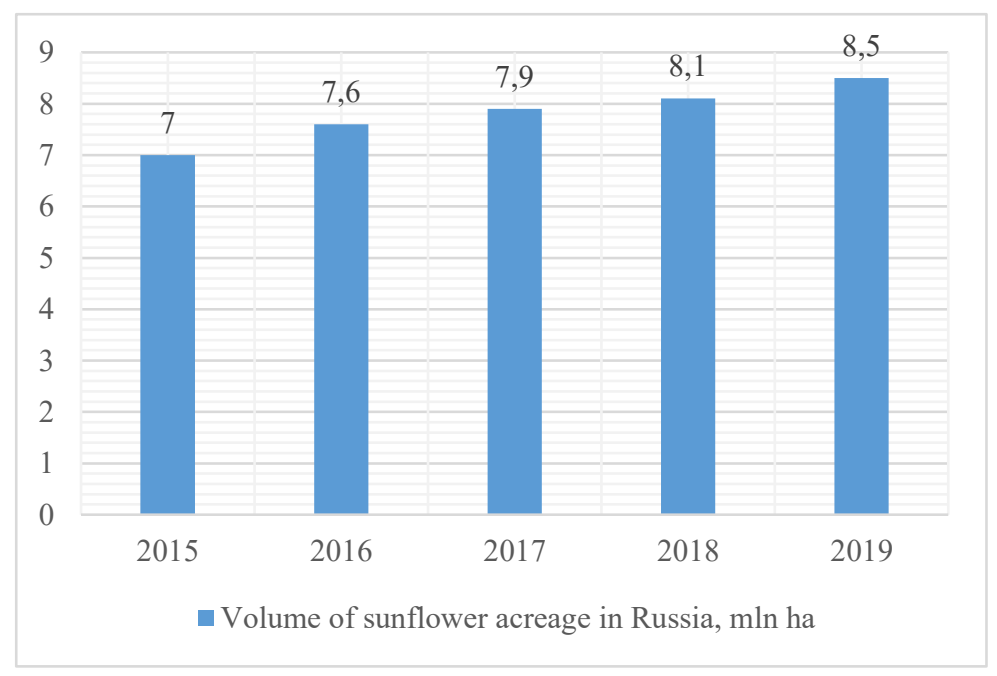

Source: composed by author from ab-centre.ru [15].

Fig. 8. The volume of sunflower acreage in Russia in 2015-2019, million hectares.

The main share of imports for sunflower production in Russia are the shipments of sunflower seeds (see Figure 9). Fertilizer and equipment used, to the contrary, are predominantly of domestic origin. This is an important notice, showing that unlike other agricultural sectors, the sulflower oil prices dependace on exchange rate is moderate at best.

Deliveries of sunflower seeds for sowing in Russia in 2019 amounted to 29,321. 2 tons, which is $5.6 \%$ (1,555. 0 tons) more than in 2018 . For five years, the volume increased by $33.9 \%$ (by 7,416. 6 tons), for ten years - by $229.5 \%$ (by 20,422.5 tons), by 2001 - by 2,530 . $1 \%$ (by 28,206. 4 tons). In January-June 2020, the volume of imports of sunflower seeds for sowing in Russia was at the level of 20,301. 2 tons, which is $10.1 \%(2,290.3$ tons $)$ less than in the same period of 2019 . 

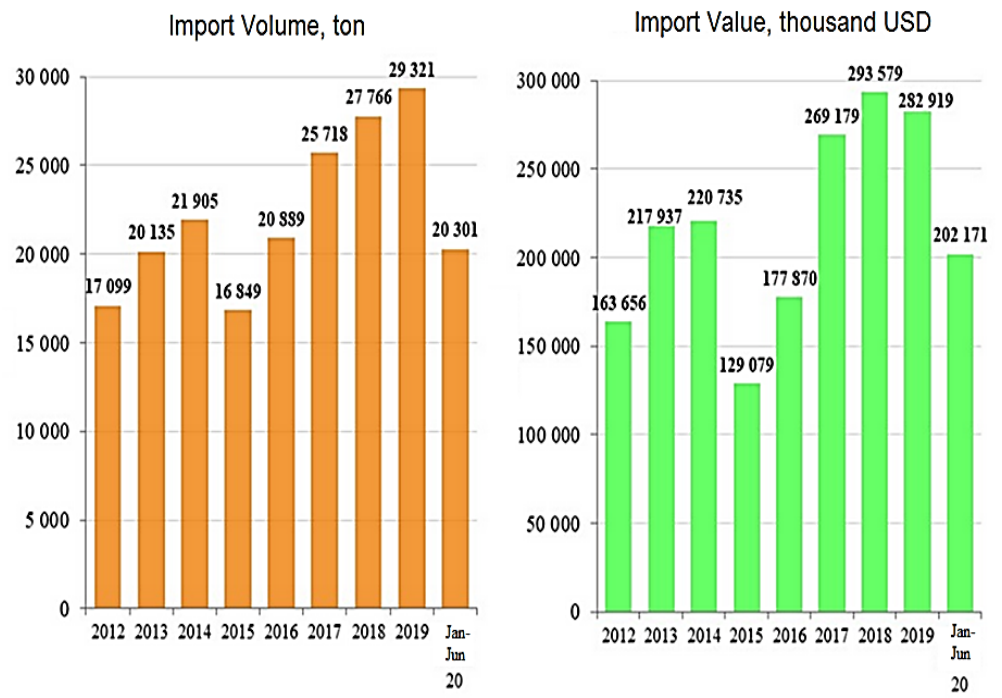

Fig. 9. The volume and cost of import of sunflower seeds for sowing in Russia in 2019 [16].

The largest market segment of sunflower is the production of sunflower oil. Oil, in turn, is used in the food industry as an ingredient for the production of semi-finished products or final food products, and is also bottled as a final product. About $90 \%$ of sunflower oil is used in cooking, less than $10 \%$ goes to the production of margarine. It is important to notice that the consumption of sunflower oil (both refined and non-refined) is deeply embedded into daily household routines. The consumption of soya or palm oils for the purpose of preparing meals is extremely low, thus making the market in question a crucial pillar of social stability and economy [17].

On the average, Russians consume approximately $30 \mathrm{~kg}$ of sunflower oil per capita, which is higher than almost anywhere else in the world. At the same time, the preceding analysis shows a clear export pattern in the market construction. While the home market provides the "bulk" sales to the main producers, the "profit" part of commerce lays beyond the national border. Operating in the market economy, over several decades the sunflower oil producers were balancing between the higher profits and domestic market share, and comparing the opportunity costs of selling internally and externally. The increase in the world sunflower oil prices with simultaneous drop in domestic target audience revenues provoked a rise in the product cost on the shelves of Russian stores. Since Russia exports almost $40 \%$ of the sunflower oil produced, companies sought to keep the pre-crisis margin and even saw the opportunity to earn extra profits from the situation.

In December 2020, the Ministry of Industry and Trade, the Ministry of Agriculture, the largest Russian retailers and food producers signed agreements to stabilize prices for sunflower oil in order to contain inflation after a sharp increase in prices caused by a low harvest in the Black Sea region. According to the agreements, the selling prices at the manufacturing plants should be no higher than 36 rubles for sugar, and no higher than 95 rubles for sunflower oil. In retail, prices should be no more than 46 rubles for sugar, and no more than 110 rubles for butter. On March 30, the Russian government extended the agreements on the stabilization of sunflower oil prices until October 1, 2021 [18].

The Russian government also offered a subsidy of 10 rubles per liter of sunflower oil to maintain a stable supply of sunflower oil to the domestic market. The subsidy is expected to last until September 2021 to ensure that the industry can adhere to the fixed price agreements for retail sunflower oil that the government introduced earlier. The quota will 
be distributed among all market participants who supply bottled sunflower oil to the domestic market. According to experts, the costs of the industry can reach up to 19 billion rubles (256 million dollars). Currently, the Ministry of Agriculture of Russia is implementing measures aimed at improving the competitiveness of the industry. Among them are subsidies that stimulate the production of oilseeds, and concessional lending at a rate of $1 \%$ to $5 \%$ [19]

Finally, after long preparation and research, the government has announced Russia's new export duty on sunflower of $50 \%$, up from $30 \%$ currently, with a minimum of $\$ 320 /$ tonne. A formula-based export tax on sunflower oil will run for one year starting $1 \mathrm{st}$ of Sept 2021.

\section{Conclusions}

The measures taken by the government drew strong criticism from industry representatives. The latter stated that in the conditions of the existing "export disparity" in the market, that is, with the divergence of prices in the domestic and foreign markets, the lost income of sunflower oil producers from sales in the domestic market is 30-40 thousand rubles per 1 ton. The freezing of prices for sunflower oil has led to large losses for producers, which are estimated at 15 billion rubles. At the same time, by the end of 2021, manufacturers may lose more than 50 billion rubles.

Critics also stressed that the strengthening of state regulation in the domestic market and the introduction of export duties will have negative consequences in the long term, since none of the major processors will build serious plans for the development of exports, since the situation in the domestic market can cancel them out. And this, in turn, significantly limits the planning horizon of producers: no one will invest in processing in the target markets, no one will seriously invest in quality.

Despite the fact that this feedback from the expert community should be taken carefully, the sequence of decisive actions of the government in relation to one of the most profitable and export-oriented branches of agriculture in Russia allows us to draw important conclusions. First, these actions showed that the government's priority is to meet the needs of the domestic market, and not the profitability of producers or export revenues. The needs of globalization and participation in the world economy are clearly declared secondary to the problems of the national economy, which is an extremely serious change from the previous 30 years of the evolution of the Russian economy and the "orientation towards foreign investment". Secondly, the nature of the measures introduced is obviously more favorable to large companies that have significant lobbying and lending opportunities to meet these new conditions. This is a sign of the rapid consolidation of the industry and the displacement of small and even medium-sized processing companies from it, which generally indicates a further movement towards the formation of state capitalism in the Chinese format. Given the importance of the industry for domestic consumption, with the next jumps in world prices for sunflower oil, it is quite possible to expect the creation of another state corporation, following the example of Rostec, Rosneft, etc., responsible for the umbrella regulation of this strategically important industry for the country.

\section{References}

1. Ukraine and Russia on the global market of sunflower oil — strong leadership positions, https://www.apk-inform.com

2. Food Outlook 2019, http://www.fao.org

3. N. Shevtsova, A. Kogteva, Scientific result Economic research, 6, 2 (2020) 
4. A. Baryshpolets, S. Devadoss, European Review Of Agricultural Economics, jbab017 (2021)

5. A. Koocheki, M. Nassiri, S. Gliessman, A. Zarea, J. of Sustainable Agriculture, 32(1), 95 (2008)

6. Russia gradually increases its presence on the global market of sunflower oil, , https://www.apk-inform.com

7. F. Santeramo, L. Di Gioia, E. Lamonaca, Land Use Policy, 101, 105102 (2020)

8. Worldwide oilseed production by type, https://www.statista.com

9. J. Cui, J. Martin, Energy Economics, 65, 148 (2017)

10. A. T. Rahoveanu, M. Rahoveanu, R. Ion, Land Use Policy, 71, 261 (2018)

11. Economic data, Global price of Sunflower Oil, https://fred.stlouisfed.org

12. A. Cheptea, C. Gaigné, European Review of Agricultural Economics, 2, 684 (2020)

13. Russia gradually increases its presence on the global market of sunflower oil, https://www.apk-inform.com

14. B. Xiong, F.Yi, Y. Li, China Agricultural Economic Review, 2, 303 (2017)

15. Sown areas of sunflower in Russia, Results of 2019, https://ab-centre.ru

16. Analysis of sunflower seed import for sowing in Russia, https://www.oilworld.ru

17. K. Bentsen, P. E. Pedersen, British Food J., 3, 1083 (2021)

18. D. Ternovsky, N. Shagaida, Economic Development of Russia, 1, 24 (2021)

19. M. Mironova, Modern economy: problems, solutions, prospects: collection of scientific papers, 347 (2021) 